\title{
PENGARUH PENGGUNAAN SELEBRITI AGNES MONICA TERHADAP MINAT BELI KONSUMEN (STUDI KASUS: NEW ERA, PROVIDER 3, HONDA VARIO, CHITATO, DAN SHAMPO ZINC)
}

\section{Debby Arthur Harris}

Email: debby_arthur_harris@yahoo.com

\section{Penulis}

Debby Arthur Harris adalah staf pengajar di Universitas Tarumanagara.

\begin{abstract}
Abstrak
This research aims to determine the influence of celebrity attractiveness $(X 1)$, celebrity credibility (X2), the fit between the celebrity and the product category (X3), and advertising weight (X4) on consumer purchase intention (Y). It is based on five brands as case studies: New Era shoe, 3 telco provider, Honda Vario motorcycle, Chitato snack, and Zinc shampoo. F test showed that the simultaneous influence of the independent variables was statistically significant. Meanwhile, $t$ test found that celebrity attractiveness (XI) influence on purchase intention ( $Y$ ) was significant only for Provider 3 case, whereas the other 3 independent variables had significant influence in all cases.Thus, in choosing celebrity endorser, advertisers are advised to consider the fit between the celebrity and the product category, advertising weight, and celebrity credibility.
\end{abstract}

\section{Key Words}

Celebrity endorser, Advertising 


\section{PENDAHULUAN}

Di era ini, iklan menjadi salah satu faktor yang penting untuk perusahaan dalam melakukan kegiatan promosi. Iklan merupakan salah satu media yang digunakan untuk menyampaikan pesan kepada konsumen. Sebagai proses komunikasi, periklanan menekankan pada pengolahan pesan. Perusahaan berharap agar pesan yang disampaikan sesuai dengan harapan perusahaan sehingga barang atau jasa yang ditawarkan dapat diterima oleh konsumen.

Sebagian perusahaan menggunakan selebriti sebagai bintang iklan suatu merk. Hal itu disebabkan karena selebriti telah menjadi bagian dari budaya sampai saat ini. Penggunaan selebriti sebagai bintang iklan merk dapat dilihat di berbagai media elektronik dan media cetak. Secara tidak langsung, dapat dikatakan bahwa selebriti dapat memiliki pengaruh yang besar terhadap perilaku masyarakat karena selebriti dijadikan sebagai salah satu public figure yang merupakan contoh untuk masyarakat untuk hal yang baik maupun yang buruk.

Pemilihan dan penggunaan selebriti untuk mempromosikan suatu merk merupakan suatu hal yang penting untuk diperhatikan. Hal tersebut ditujukan untuk meningkatkan minat beli konsumen terhadap suatu merk. Oleh karena itu, selebriti sebagai bintang iklan suatu merk, harus dilihat dari daya tarik dan kredibilitas dari selebriti itu sendiri. Selain itu, selebriti yang digunakan sebagai bintang iklan suatu merk, harus memiliki kecocokan dengan kategori produk yang akan diiklankan. Hal ini dimaksudkan agar selebriti dapat membangun kepercayaan dan menciptakan dorongan untuk memberikan rekomendasi kepada konsumen tetap dan atau calon konsumen.

Kerancuan konsumen dalam menerima pesan dalam iklan yang disampaikan oleh seorang selebriti dapat terjadi akibat seorang selebriti sebagai bintang iklan lebih dari satu merk. Terdapat beberapa faktor yang menjadikan perusahaan memilih selebriti yang telah menjadi bintang iklan merk lain yaitu selebriti tersebut merupakan public figure yang terkenal pada saat itu, selebriti memiliki karakteristik yang sesuai dengan produk suatu merk, selebriti memiliki daya tarik untuk mengajak, selebriti diyakini dapat meningkatkan daya beli konsumen, dan sebagainya. 
Agnes Monica merupakan salah satu selebriti Indonesia yang sampai saat ini paling banyak digunakan sebagai endorser berbagai merk. Beberapa merk yang dengan menggunakan Agnes Monica sebagai bintang iklan adalah New Era, Honda Vario, Zinc, operator selular 3, Chitato, dan sebagainya. Daya tarik, karakteristik, kecocokan Agnes Monica dengan kategori produk, dan intensitas iklan merupakan beberapa faktor yang harus diperhatikan apabila perusahaan tertarik menjadikan Agnes Monica sebagai endorser suatu merk.

Perusahaan harus memperhatikan beberapa hal apabila ingin menggunakan Agnes Monica sebagai bintang iklan suatu merk. Penelitian ini membantu perusahaan untuk melihat pengaruh penggunaan endorser melalui daya tarik yang dimiliki Agnes Monica, kepribadian Agnes Monica, kecocokan Agnes Monica dengan kategori produk, dan intensitas iklan sebagai sarana komunikasi kepada konsumen terhadap minat beli konsumen.

\section{TUJUAN PENELITIAN}

Penelitian yang dilakukan ini bertujuan untuk menganalisis pengaruh faktor faktor yang berkaitan dengan Agnes Monica sebagai bintang iklan (daya tarik, kredibilitas, kecocokan dengan kategori produk, dan intensitas iklan) terhadap minat beli konsumen. Analisis pengaruh tersebut akan dilakukan secara simultan dan parsial.

\section{TINJAUAN PUSTAKA}

\section{Endorser}

Pengertian selebriti menurut Shimp (2003) adalah tokoh (aktor, penghibur, atau atlet) yang dikenal masyarakat karena prestasinya. Dari beberapa pengertian tersebut dapat dikatakan bahwa selebriti merupakan seseorang yang diketahui oleh masyarakat luas. Publisitas yang diketahui masyarakat, biasanya sekitar kehidupan dari selebriti tersebut.

Penggunaan selebriti sebagai bintang iklan suatu merk, dipercaya dapat mempengaruhi minat beli konsumen untuk meningkatkan penjualan produk tersebut. Hal itu disebabkan karena selebriti dapat meningkatkan perhatian (attention) dan daya ingat 
(recall) konsumen terhadap suatu merk. Selain itu, selebriti dimaksudkan agar dapat mewakili kepribadian dari merk dan diharapkan dapat dekat dengan konsumen.

Sebagian besar perusahaan menggunakan selebriti sebagai juru bicara untuk mempromosikan suatu produk untuk meyakinkan konsumen untuk menarik konsumen dalam melakukan pembelian. Beberapa selebriti yang digunakan sebagai endorser adalah Agnes Monica (New Era, Provider 3, Honda Vario, Chitato, Shampo Zinc, dan sebagainya), Yuanita Christiani (Rapika dan Sasa), Jeng Kelin (Sharp dan Rapika), dan lainnya.

Shimp (2003) menyatakan bahwa pemasang iklan menggunakan selebriti karena atribut kepopuleran yang dimiliki (seperti kecantikan, bakat, dan sebagainya). Selain itu, menurut Solomon (2002) selebriti yang digunakan sebagai daya tarik yang mengacu pada penampilan fisik, kepribadian, kesukaan, dan kesamaan dengan konsumen akan memberikan respons positif konsumen.

Ohanian (1991) menyatakan bahwa penggunaan selebriti yang menarik sebagai juru bicara akan memberikan respons yang lebih baik. Shimp (2003) menyatakan bahwa asosiasi yang dilakukan secara berulang oleh selebriti terhadap suatu merk akan membuat konsumen merasa serupa dengan selebriti. Selain itu, kemungkinan konsumen hanya menyukai selebriti tersebut.

Khatri (2006) menyatakan bahwa selebriti banyak digunakan untuk mempercepat ingatan konsumen akan produk dan dapat mempengaruhi konsumen dalam melakukan pembelian. Selebriti yang dapat mempengaruhi masyarakat dalam melakukan pembelian biasanya yang akrab dengan masyarakat. Bintang iklan selain selebriti biasanya dapat berasal dari kalangan olahragawan, model, penyanyi, dan sebagainya.

Kotler dan Armstong (2008) mengatakan bahwa kesalahan dalam memilih endorser akan menimbulkan rasa malu dan citra yang buruk. Oleh karena itu, terdapat beberapa hal yang perlu diperhatikan oleh perusahaan dalam memilih selebriti sebagai endorser untuk mendukung suatu merk yaitu:

\section{a. Kredibilitas selebriti}

Selebriti dapat menguasai merk yang akan diiklankan dan dapat dipercaya sehingga membuat konsumen percaya dan yakin. 


\section{b. Kecocokan dengan masyarakat}

Selebriti yang digunakan sebagai bintang iklan harus memiliki penilaian yang baik di masyarakat.

\section{c. Kecocokan dengan merk}

Citra, nilai, dan perilaku selebriti harus sesuai dengan kesan merk yang akan diiklankan.

\section{d. Daya tarik}

Selebriti memiliki kemampuan untuk menarik konsumen (seperti keramahan, kecantikan, dan sebagainya).

\section{Perilaku Kosumen}

Pemahaman mengenai perilaku konsumen dalam pembelian suatu barang atau jasa dibutuhkan studi tersendiri dikarenakan perilaku konsumen sangat kompleks. Beberapa pengertian perilaku konsumen menurut para ahli. Menurut Solomon (2002), definisi perilaku konsumen adalah:

"The processes involve when individuals or groups select, purchase, use, or dispose of products, services, ideas, or experiences to satisfy needs and desires." (p.5)

Menurut Hawkins dan Mothersbaugh (2010), definisi perilaku konsumen adalah:

"Study of individual, group or organization and the processes they use to select, secure, use, and dispose of the product, service, experience, or ideas to satisfy desires and impact of the process for consumers." (p.6)

Kotler dan Armstrong (2008) menyatakan bahwa proses keputusan memilih barang atau jasa dapat dipengaruhi oleh faktor eksternal dan faktor internal. Beberapa faktor tersebut adalah:

\section{a. Faktor budaya}

Budaya merupakan faktor mendasar dalam pembentukan norma-norma yang dimiliki seseorang dan selanjutnya membentuk perilaku sebagai seorang konsumen. 
Budaya meliputi hal-hal yang dipelajari dari keluarga, tetangga, teman, guru, dan tokoh-tokoh masyarakat. Beberapa hal yang termasuk dalam budaya adalah:

1) Nilai-nilai yang merupakan norma yang dianut masyarakat.

2) Persepsi yang merupakan cara pandang pada sesuatu.

3) Prefensi yang merupakan rasa lebih suka pada sesuatu dibandingkan dengan yang lainnya.

4) Behavior yang merupakan suatu kebiasaan yang telah sering dilakukan.

\section{b. Faktor sosial}

Terdapat beberapa faktor sosial yang dapat diperhatikan dalam menentukan perilaku konsumen yaitu:

\section{1) Reference group}

Kelompok yang dapat mempengaruhi anggotanya membuat keputusan pembelian sesuatu barang atau jasa meskipun ada pengecualian pada sebagian orang.

\section{2) Keluarga}

Keluarga merupakan salah satu faktor penting dalam mempengaruhi anggota keluarga dalam memilih suatu barang atau jasa.

\section{3) Peran dan status}

Peran seseorang di masyarakat atau di perusahaan akan mempengaruhi pola tindakanya dalam membeli barang dan jasa (disebut berbelanja).

\section{c. Faktor teknologi}

Perkembangan teknologi yang terus berkembang dapat dijadikan sebagai salah satu hal yang menentukan perilaku konsumen seperti:

1) Transfortasi pribadi yang terus mengalami perkembangan dari tahun ke tahun.

2) Peralatan rumah tangga yang berkembang secara pesat.

3) Audio visual yang diminati dari waktu ke waktu dan dapat dinikmati oleh diri sendiri maupun untuk keluarga.

4) Internet dan seluler yang semakin berkembang dan meningkatkan pasar hardware. 
Dalam suatu proses pembelian konsumen selalu melalui beberapa tahapan. Menurut Kotler dan Armstrong (2008), tahapan tersebut adalah sebagai berikut:

\section{a. Need Recognition}

Keadaan konsumen akan kebutuhan terhadap suatu produk atau jasa. Kebutuhan konsumen dapat dipengaruhi oleh faktor internal (seperti rasa lapar, haus, dan lainnya) atau faktor eksternal (seperti pengaruh kelompok sosial, tren dan lainnya)

\section{b. Information Search}

Konsumen berusaha untuk mencari informasi yang diperlukan dalam memenuhi kebutuhannya. Informasi dapat diperoleh melalui berbagai sumber yaitu:

1) Lingkungan sekitar seperti keluarga, teman, tetangga, dan sebagainya.

2) Sumber publik seperti media massa, komunitas, dan lainnya.

3) Sumber Komersil seperti iklan, kemasan, pameran dan lainnya.

4) Uji coba.

\section{c. Evaluation of Alternatives}

Setelah konsumen mendapatkan informasi yang cukup maka terdapat beberapa alternative yang dapat dijadikan sebagai pilihan.

\section{d. Purchase decision}

Pada tahap ini, secara tidak sadar konsumen akan memberikan peringkat terhadap beberapa alternative pilihan yang ada. Konsumen cenderung akan memilih produk dengan peringkat tertinggi.

\section{e. Post Purchase Behaviour}

Konsumen akan melihat dan merasakan kesesuaian antara harapan sebelum membeli produk dan setelah membeli produk. Apabila, produk tersebut dapat memenuhi kebutuhan konsumen, maka konsumen akan merasa puas karena kebutuhannya dapat terpenuhi.

Keputusan dalam membeli suatu barang atau jasa seringkali melibatkan dua pihak atau lebih. Menurut Assauri (2009), terdapat lima peran dalam proses pengambilan keputusan pembelian yaitu: 
a. Pemprakarsa (initiator) adalah seseorang yang pertama kali menyarankan ide untuk melakukan pembelian.

b. Pembawa pengaruh (influencer) adalah seseorang yang memiliki pandangan atau nasihat yang mempengaruhi keputusan dalam melakukan suatu pembelian.

c. Pengambil keputusan (decider) adalah seseorang yang menentukan keputusan untuk melakukan pembelian barang atau jasa.

d. Pembeli (buyer) adalah seseorang yang melakukan pembelian secara nyata.

e. Pemakai (user) adalah seseorang yang mengkonsumsi dan menggunakan barang atau jasa.

\section{KERANGKA PEMIKIRAN}

Endorser dapat mempengaruhi seseorang untuk membeli suatu barang atau jasa. Beberapa faktor yang digunakan untuk menganalisis pengaruh minat beli konsumen adalah daya tarik dari endorser tersebut, kredibilitas yang dimiliki oleh endorser, kecocokan endorser dengan kategori produk yang diiklankan, dan intensitas iklan juga perlu diperhatikan.

Dengan adanya beberapa faktor tersebut, dapat mendorong konsumen untuk meningkatkan minat beli terhadap suatu produk atau jasa. Dalam penelitian ini, endorser yang dimaksudkan adalah Agnes Monica dan produk yang diiklankan olehnya adalah New Era, provider GSM 3, Honda Vario, Chitato, dan shampo Zinc.

\section{METODOLOGI PENELITIAN}

Jenis penelitian ini merupakan penelitian sebab akibat (causal research) dari data kualitatif yang telah dikuantitatifkan sehingga data yang ada dapat diolah. Hal ini dimaksudkan agar dapat mengetahui minat beli masyarakat apabila perusahaan menggunakan selebriti sebagai bintang iklan dilihat dari daya tarik selebriti, kredibilitas selebriti, kecocokan selebriti dengan kategori produk, dan intensitas iklan.

Dalam mengumpulkan data untuk peelitia ini,teknik pengumpulan data yang dilakukan penulis adalah sebagai berikut: 


\section{a. Library Research ( Riset Kepustakaan)}

Studi kepustakaan adalah metode penelitian yang dilakukan didalam perpustakaan, dengan cara membaca, mengumpulkan, mencatat serta mempelajari buku-buku yang berhubungan dengan masalah yang diteliti. Data yang diperoleh merupakan data sekunder, yaitu data yang tidak berhubungan langsung dengan perusahaan. Penelitian ini dilakukan dengan cara mengumpulkan data melalui buku - buku wajib maupun buku - buku anjuran, serta sumber - sumber lainnya.

\section{b. Field Research (Riset Lapangan)}

Riset lapangan adalah metode penelitian yang dilakukan dengan mengumpukan data yang diperlukan. Pengumpuan data tersebut dilakukan dengan menyebar kuesioner kepada masyarakat di Jakarta.

Menurut Sekaran (2003), penentuan jumlah sampel dalam penelitian dapat berdasarkan perhitungan dari 5 kali dari jumlah pertanyaan dalam kuesioner atau 10 kali dari jumlah variabel penelitian. Oleh karena itu, dapat dilakukan perhitungan sebagai berikut:
a. Berdasarkan jumlah variabel : 5 variabel $\times 10=\mathbf{5 0}$ sampel
b. Berdasarkan jumlah pertanyaan : 47 pertanyaan $x 5=235$ sampel

Dari perhitungan tersebut dapat dikatakan bahwa jumlah sampel yang sesuai untuk penelitian ini adalah sebanyak 235 sampel. Untuk ketelitian yang lebih baik, jumlah sampel yang digunakan untuk penelitian ini adalah sebanyak 250 sampel.

\section{HASIL DAN ANALISIS DATA}

\section{Uji Validitas dan Reliabilitas}

Tabel berikut menunjukkan validitas dan reliabilitas dari instrumen-instrumen untuk setiap variabel dalam penelitian. 


\section{Tabel 1}

\section{Uji Validitas}

\begin{tabular}{|c|c|c|c|}
\hline No & Pernyataan & $\begin{array}{l}\text { R Pearson } \\
\text { correlation }\end{array}$ & Keterangan \\
\hline D1 & Agnes Monica memiliki paras yang cantik. & 0,498 & $\begin{array}{c}\text { VALID } \\
0,498>0,03\end{array}$ \\
\hline D2 & Agnes Monica merupakan pribadi yang ekspresif. & $\mathbf{0 , 5 5 4}$ & $\begin{array}{c}\text { VALID } \\
0,554>0,03\end{array}$ \\
\hline D3 & Agnes Monica memiliki keluwesan dalam gerak tubuh. & $\mathbf{0 , 5 0 7}$ & $\begin{array}{c}\text { VALID } \\
\mathbf{0 , 5 0 7}>\mathbf{0 , 0 3}\end{array}$ \\
\hline D4 & Agnes Monica memiliki bentuk badan yang proporsional. & 0,511 & $\begin{array}{c}\text { VALID } \\
0,511>0,03\end{array}$ \\
\hline D5 & Penampilan Agnes Monica selalu modis. & 0,515 & $\begin{array}{c}\text { VALID } \\
0,515>0,03\end{array}$ \\
\hline D6 & Agnes Monica selalu bergaya modern. & $\mathbf{0 , 4 7 8}$ & $\begin{array}{c}\text { VALID } \\
0,478>0,03\end{array}$ \\
\hline D7 & Agnes Monica memiliki tubuh yang sehat. & 0,643 & $\begin{array}{c}\text { VALID } \\
0,643>0,03\end{array}$ \\
\hline D8 & Agnes Monica merupakan pribadi yang cerdas. & 0,634 & $\begin{array}{c}\text { VALID } \\
0,634>0,03\end{array}$ \\
\hline D9 & Agnes Monica selalu menunjukkan semangat. & 0,565 & $\begin{array}{c}\text { VALID } \\
0,565>0,03\end{array}$ \\
\hline D10 & Agnes Monica memiliki percaya diri yang tinggi. & $\mathbf{0 , 4 9 9}$ & $\begin{array}{c}\text { VALID } \\
0,499>0,03\end{array}$ \\
\hline D11 & Agnes Monica selalu bersikap ramah. & $\mathbf{0 , 5 9 2}$ & $\begin{array}{c}\text { VALID } \\
0,592>0,03\end{array}$ \\
\hline D12 & Agnes Monica melakukan kegiatan kemasyarakatan yang positif. & 0,696 & $\begin{array}{c}\text { VALID } \\
0,696>0,03\end{array}$ \\
\hline D13 & $\begin{array}{l}\text { Agnes Monica berani mempertanggung jawabkan setiap } \\
\text { perbuatannya. }\end{array}$ & 0,640 & $\begin{array}{c}\text { VALID } \\
0,640>0,03\end{array}$ \\
\hline K14 & Agnes Monica dapat meyakinkan konsumen. & $\mathbf{0 , 7 5 3}$ & $\begin{array}{c}\text { VALID } \\
0,753>0,03\end{array}$ \\
\hline K15 & Agnes Monica menguasai produk yang diiklankan. & 0,768 & $\begin{array}{c}\text { VALID } \\
\mathbf{0 , 7 6 8 > 0 , 0 3}\end{array}$ \\
\hline K16 & Agnes Monica dapat membuat konsumen melihat fakta yang & $\mathbf{0 , 8 0 3}$ & VALID \\
\hline
\end{tabular}


Pengaruh Penggunaan Selebriti Agnes Monica Terhadap Minat Beli Konsumen (studi kasus: New Era, Provider 3, Honda Vario, Chitato, dan Shampo Zinc)

\begin{tabular}{|c|c|c|c|}
\hline & sebenarnya. & & $0,803>0,03$ \\
\hline K17 & Agnes Monica terlihat jujur dalam menyampaikan pesan dalam iklan. & $\mathbf{0 , 8 0 9}$ & $\begin{array}{c}\text { VALID } \\
\mathbf{0 , 8 0 9}>\mathbf{0 , 0 3}\end{array}$ \\
\hline $\mathrm{C} 18$ & Agnes Monica sesuai membintangi iklan produk alas kaki. & $\mathbf{0 , 8 9 5}$ & $\begin{array}{c}\text { VALID } \\
\mathbf{0 , 8 9 5}>0,03\end{array}$ \\
\hline C19 & $\begin{array}{l}\text { Agnes Monica sesuai membintangi iklan jaringan GSM untuk } \\
\text { handphone. }\end{array}$ & $\mathbf{0 , 8 9 2}$ & $\begin{array}{c}\text { VALID } \\
\mathbf{0 , 8 9 2}>\mathbf{0 , 0 3}\end{array}$ \\
\hline $\mathrm{C} 20$ & Agnes Monica sesuai membintangi iklan kendaraan bermotor. & $\mathbf{0 , 8 9 8}$ & $\begin{array}{c}\text { VALID } \\
\mathbf{0 , 8 9 8}>\mathbf{0 , 0 3}\end{array}$ \\
\hline $\mathrm{C} 21$ & Agnes Monica sesuai membintangi iklan produk snack. & $\mathbf{0 , 8 6 1}$ & $\begin{array}{c}\text { VALID } \\
\mathbf{0 , 8 6 1 > 0 , 0 3}\end{array}$ \\
\hline $\mathrm{C} 22$ & Agnes Monica sesuai membintangi iklan produk shampo. & $\mathbf{0 , 8 0 2}$ & $\begin{array}{c}\text { VALID } \\
\mathbf{0 , 8 0 2}>\mathbf{0 , 0 3}\end{array}$ \\
\hline $\mathrm{C} 23$ & Agnes Monica sesuai menjadi bintang iklan New Era. & $\mathbf{0 , 8 8 5}$ & $\begin{array}{c}\text { VALID } \\
\mathbf{0 , 8 8 5}>0,03\end{array}$ \\
\hline $\mathrm{C} 24$ & $\begin{array}{l}\text { Agnes Monica sesuai menjadi bintang iklan Provider } 3 \text { (jaringan } \\
\text { GSM untuk handphone). }\end{array}$ & $\mathbf{0 , 8 9 0}$ & $\begin{array}{c}\text { VALID } \\
\mathbf{0 , 8 9 0}>\mathbf{0 , 0 3}\end{array}$ \\
\hline $\mathrm{C} 25$ & Agnes Monica sesuai menjadi bintang iklan Honda Vario. & 0,903 & $\begin{array}{c}\text { VALID } \\
0,903>0,03\end{array}$ \\
\hline $\mathrm{C} 26$ & Agnes Monica sesuai menjadi bintang iklan Chitato. & $\mathbf{0 , 8 7 3}$ & $\begin{array}{c}\text { VALID } \\
\mathbf{0 , 8 7 3 > 0 , 0 3}\end{array}$ \\
\hline $\mathrm{C} 27$ & Agnes Monica sesuai menjadi bintang iklan shampoo Zinc. & $\mathbf{0 , 8 1 3}$ & $\begin{array}{c}\text { VALID } \\
\mathbf{0 , 8 1 3 > 0 , 0 3}\end{array}$ \\
\hline $\mathrm{I} 28$ & $\begin{array}{l}\text { Anda mengetahui adanya iklan New Era dengan endorser Agnes } \\
\text { Monica. }\end{array}$ & $\mathbf{0 , 6 5 0}$ & $\begin{array}{c}\text { VALID } \\
0,650>0,03\end{array}$ \\
\hline I29 & $\begin{array}{l}\text { Anda mengetahui adanya iklan Provider } 3 \text { (jaringan GSM untuk } \\
\text { handphone) dengan endorser Agnes Monica. }\end{array}$ & 0,776 & $\begin{array}{c}\text { VALID } \\
0,776>0,03\end{array}$ \\
\hline $\mathrm{I} 30$ & $\begin{array}{l}\text { Anda mengetahui adanya iklan Honda Vario dengan endorser Agnes } \\
\text { Monica. }\end{array}$ & 0,814 & $\begin{array}{c}\text { VALID } \\
\mathbf{0 , 8 1 4}>\mathbf{0 , 0 3}\end{array}$ \\
\hline I31 & $\begin{array}{l}\text { Anda mengetahui adanya iklan Chitato dengan endorser Agnes } \\
\text { Monica. }\end{array}$ & 0,781 & $\begin{array}{c}\text { VALID } \\
\mathbf{0 , 7 8 1}>\mathbf{0 , 0 3}\end{array}$ \\
\hline $\mathrm{I} 32$ & $\begin{array}{l}\text { Anda mengetahui adanya iklan Shampo Zinc dengan endorser Agnes } \\
\text { Monica. }\end{array}$ & 0,769 & $\begin{array}{c}\text { VALID } \\
\mathbf{0 , 7 6}>\mathbf{0 , 0 3}\end{array}$ \\
\hline I33 & $\begin{array}{l}\text { Anda mengetahui adanya iklan New Era dengan endorser Agnes } \\
\text { Monica sering ditayangkan di televisi. }\end{array}$ & 0,751 & $\begin{array}{c}\text { VALID } \\
\mathbf{0 , 7 5 1 > 0 , 0 3}\end{array}$ \\
\hline
\end{tabular}




\begin{tabular}{|c|c|c|c|}
\hline I34 & $\begin{array}{l}\text { Iklan Provider } 3 \text { (jaringan GSM untuk handphone) dengan endorser } \\
\text { Agnes Monica sering ditayangkan di televisi. }\end{array}$ & 0,790 & $\begin{array}{c}\text { VALID } \\
\mathbf{0 , 7 9 0}>\mathbf{0 , 0 3}\end{array}$ \\
\hline I35 & $\begin{array}{l}\text { Iklan Honda Vario dengan endorser Agnes Monica sering } \\
\text { ditayangkan di televisi. }\end{array}$ & 0,854 & $\begin{array}{c}\text { VALID } \\
\mathbf{0 , 8 5 4}>\mathbf{0 , 0 3}\end{array}$ \\
\hline I36 & $\begin{array}{l}\text { Iklan Chitato dengan endorser Agnes Monica sering ditayangkan di } \\
\text { televisi. }\end{array}$ & $\mathbf{0 , 8 5 4}$ & $\begin{array}{c}\text { VALID } \\
\mathbf{0 , 8 5 4}>\mathbf{0 , 0 3}\end{array}$ \\
\hline I37 & $\begin{array}{l}\text { Iklan Shampo Zinc dengan endorser Agnes Monica sering } \\
\text { ditayangkan di televisi. }\end{array}$ & 0,856 & $\begin{array}{c}\text { VALID } \\
\mathbf{0 , 8 5 6}>\mathbf{0 , 0 3}\end{array}$ \\
\hline $\mathrm{I} 38$ & $\begin{array}{l}\text { Iklan New Era dengan endorser Agnes Monica ditayangkan akhir- } \\
\text { akhir ini. }\end{array}$ & 0,670 & $\begin{array}{c}\text { VALID } \\
\mathbf{0 , 6 7 0}>\mathbf{0 , 0 3}\end{array}$ \\
\hline I39 & $\begin{array}{l}\text { Iklan Provider } 3 \text { (jaringan GSM untuk handphone) dengan endorser } \\
\text { Agnes Monica ditayangkan akhir-akhir ini. }\end{array}$ & 0,713 & $\begin{array}{c}\text { VALID } \\
\mathbf{0 , 7 1 3}>\mathbf{0 , 0 3}\end{array}$ \\
\hline I40 & $\begin{array}{l}\text { Iklan Honda Vario dengan endorser Agnes Monica ditayangkan } \\
\text { akhir-akhir ini. }\end{array}$ & 0,732 & $\begin{array}{c}\text { VALID } \\
\mathbf{0 , 7 3 2 > 0 , 0 3}\end{array}$ \\
\hline I41 & $\begin{array}{l}\text { Iklan Chitato dengan endorser Agnes Monica ditayangkan akhir-akhir } \\
\text { ini. }\end{array}$ & 0,736 & $\begin{array}{c}\text { VALID } \\
\mathbf{0 , 7 3 6 > 0 , 0 3}\end{array}$ \\
\hline I42 & $\begin{array}{l}\text { Iklan Shampo Zinc dengan endorser Agnes Monica ditayangkan } \\
\text { akhir-akhir ini. }\end{array}$ & $\mathbf{0 , 8 3 3}$ & $\begin{array}{c}\text { VALID } \\
\mathbf{0 , 8 3 3}>\mathbf{0 , 0 3}\end{array}$ \\
\hline
\end{tabular}

Sumber: Data diolah dari kuesioner dengan menggunakan SPSS version 15 for windows

Tabel 2

Uji Reliabilitas

\begin{tabular}{|c|c|c|c|}
\hline No & Variabel & Cronbach's Alpha & Keterangan \\
\hline 1 & Daya tarik Agnes Monica $\left(\mathrm{X}_{1}\right)$ & 0,742 & $\begin{array}{r}\text { RELIABEL } \\
0,742>0,6\end{array}$ \\
\hline 2 & Kredibilitas Agnes Monica $\left(\mathrm{X}_{2}\right)$ & $\mathbf{0 , 8 1 0}$ & $\begin{array}{r}\text { RELIABEL } \\
0,810>0,6\end{array}$ \\
\hline 3 & $\begin{array}{l}\text { Kecocokan Agnes Monica dengan kategori produk }\left(\mathrm{X}_{3}\right) \text { (studi } \\
\text { kasus: New Era) }\end{array}$ & 0,888 & $\begin{array}{r}\text { RELIABEL } \\
\mathbf{0 , 8 8 8}>\mathbf{0 , 6}\end{array}$ \\
\hline 4 & $\begin{array}{l}\text { Kecocokan Agnes Monica dengan kategori produk }\left(\mathrm{X}_{3}\right) \text { (studi } \\
\text { kasus: Provider } 3 \text { ) }\end{array}$ & $\mathbf{0 , 8 8 9}$ & $\begin{array}{r}\text { RELIABEL } \\
0,889>0,6\end{array}$ \\
\hline 5 & $\begin{array}{l}\text { Kecocokan Agnes Monica dengan kategori produk }\left(\mathrm{X}_{3}\right) \text { (studi } \\
\text { kasus: Honda Vario) }\end{array}$ & 0,894 & $\begin{array}{r}\text { RELIABEL } \\
0,894>0,6\end{array}$ \\
\hline
\end{tabular}




\begin{tabular}{|c|c|c|c|}
\hline 6 & $\begin{array}{l}\text { Kecocokan Agnes Monica dengan kategori produk }\left(\mathrm{X}_{3}\right) \text { (studi } \\
\text { kasus: Chitato) }\end{array}$ & 0,876 & $\begin{array}{r}\text { RELIABEL } \\
0,876>0,6\end{array}$ \\
\hline 7 & $\begin{array}{l}\text { Kecocokan Agnes Monica dengan kategori produk }\left(\mathrm{X}_{3}\right) \text { (studi } \\
\text { kasus: Shampo Zinc) }\end{array}$ & $\mathbf{0 , 8 3 8}$ & $\begin{array}{r}\text { RELIABEL } \\
\mathbf{0 , 8 3 8}>\mathbf{0 , 6}\end{array}$ \\
\hline 8 & $\begin{array}{l}\text { Intensitas iklan yang dibintangi oleh Agnes Monica }\left(\mathrm{X}_{4}\right) \text { (studi } \\
\text { kasus: New Era) }\end{array}$ & 0,767 & $\begin{array}{r}\text { RELIABEL } \\
0,767>0,6\end{array}$ \\
\hline 9 & $\begin{array}{l}\text { Intensitas iklan yang dibintangi oleh Agnes Monica }\left(\mathrm{X}_{4}\right) \text { (studi } \\
\text { kasus: Provider } 3 \text { ) }\end{array}$ & $\mathbf{0 , 8 0 8}$ & $\begin{array}{r}\text { RELIABEL } \\
0,808>0,6\end{array}$ \\
\hline 10 & $\begin{array}{l}\text { Intensitas iklan yang dibintangi oleh Agnes Monica }\left(\mathrm{X}_{4}\right) \text { (studi } \\
\text { kasus: Honda Vario) }\end{array}$ & $\mathbf{0 , 8 2 7}$ & $\begin{array}{r}\text { RELIABEL } \\
\mathbf{0 , 8 2 7}>\mathbf{0 , 6}\end{array}$ \\
\hline 11 & $\begin{array}{l}\text { Intensitas iklan yang dibintangi oleh Agnes Monica }\left(\mathrm{X}_{4}\right) \text { (studi } \\
\text { kasus: Chitato) }\end{array}$ & $\mathbf{0 , 8 2 3}$ & $\begin{array}{r}\text { RELIABEL } \\
\mathbf{0 , 8 2 3}>\mathbf{0 , 6}\end{array}$ \\
\hline 12 & $\begin{array}{l}\text { Intensitas iklan yang dibintangi oleh Agnes Monica }\left(\mathrm{X}_{4}\right) \text { (studi } \\
\text { kasus: Shampo Zinc) }\end{array}$ & $\mathbf{0 , 8 3 5}$ & $\begin{array}{r}\text { RELIABEL } \\
\mathbf{0 , 8 3 5}>\mathbf{0 , 6}\end{array}$ \\
\hline
\end{tabular}

Sumber: Data diolah dari kuesioner dengan menggunakan SPSS version 15 for windows

\section{Uji Asumsi Klasik untuk setiap studi kasus}

Tabel berikut menunjukkan hasil dari pengujian asumsi klasik yang dilakukan untuk setiap studi kasus.

\section{Tabel 3}

Uji Asumsi Klasik (Studi Kasus: New Era)

\begin{tabular}{|c|c|c|}
\hline Uji Asumsi & Nilai yang Diuji & KESIMPULAN \\
\hline Multikolinearitas & VIF $=2,322$ & Tidak ada multikolinearitas \\
& & $2,322<10$ \\
\hline Heteroskedastisitas & Scatter plot: & Tidak ada heteroskedastisitas \\
\hline titik-titik menyebar & Normal P-P Plot: \\
& titik-titik sekitar garis & Ada normalitas \\
\hline
\end{tabular}


Sumber: Data diolah dari kuesioner dengan menggunakan SPSS version 15 for windows

\section{Tabel 4}

\section{Uji Asumsi Klasik (Studi Kasus: Provider 3)}

\begin{tabular}{|c|c|c|}
\hline Uji Asumsi & Nilai yang Diuji & KESIMPULAN \\
\hline Multikolinearitas & VIF $=2,053$ & Tidak ada multikolinearitas \\
& & $2,053<10$ \\
\hline Heteroskedastisitas & $\begin{array}{c}\text { Scatter plot: } \\
\text { titik-titik menyebar }\end{array}$ & Tidak ada heteroskedastisitas \\
\hline Normalitas & $\begin{array}{c}\text { Normal P-P Plot: } \\
\text { titik-titik sekitar garis }\end{array}$ & Ada normalitas \\
\hline
\end{tabular}

Sumber: Data diolah dari kuesioner dengan menggunakan SPSS version 15 for windows

\section{Tabel 5}

Uji Asumsi Klasik (Studi Kasus: Honda Vario)

\begin{tabular}{|c|c|c|}
\hline Uji Asumsi & Nilai yang Diuji & KESIMPULAN \\
\hline Multikolinearitas & VIF $=2,721$ & Tidak ada multikolinearitas \\
& & $2,721<10$ \\
\hline Heteroskedastisitas & Scatter plot: & Tidak ada heteroskedastisitas \\
\hline titik-titik menyebar & Normal P-P Plot: & Ada normalitas \\
\hline
\end{tabular}

Sumber: Data diolah dari kuesioner dengan menggunakan SPSS version 15 for windows 


\section{Tabel 6}

Uji Asumsi Klasik (Studi Kasus: Chitato)

\begin{tabular}{|c|c|c|}
\hline Uji Asumsi & Nilai yang Diuji & KESIMPULAN \\
\hline Multikolinearitas & VIF $=2,744$ & Tidak ada multikolinearitas \\
& & $2,744<10$ \\
\hline Heteroskedastisitas & Scatter plot: & Tidak ada heteroskedastisitas \\
\hline titik-titik menyebar & Normal P-P Plot: \\
& titik-titik sekitar garis & Ada normalitas \\
\hline
\end{tabular}

Sumber: Data diolah dari kuesioner dengan menggunakan SPSS version 15 for windows

\section{Tabel 7}

\section{Uji Asumsi Klasik (Studi Kasus: Shampo Zinc)}

\begin{tabular}{|c|c|c|}
\hline Uji Asumsi & Nilai yang Diuji & KESIMPULAN \\
\hline Multikolinearitas & VIF $=2,712$ & Tidak ada multikolinearitas \\
& & $2,712<10$ \\
\hline Heteroskedastisitas & $\begin{array}{c}\text { Scatter plot: } \\
\text { titik-titik menyebar }\end{array}$ & Tidak ada heteroskedastisitas \\
\hline Normalitas & $\begin{array}{c}\text { Normal P-P Plot: } \\
\text { titik-titik sekitar garis }\end{array}$ & Ada normalitas \\
\hline
\end{tabular}

Sumber: Data diolah dari kuesioner dengan menggunakan SPSS version 15 for windows

\section{ANALISIS REGRESI}

Setelah dilakukan pengujian asumsi klasik maka dilakukan analisis regresi untuk setiap studi kasus yang ditujukkan dalam tabel berikut: 
Tabel 8

\section{Pengujian secara simultan (ANOVA)}

\begin{tabular}{|c|c|c|}
\hline Studi Kasus & Sig. ANOVA & KESIMPULAN \\
\hline New Era & 0.000 & Ho Ditolak (sig.) \\
& & $0.000<0.05$ \\
\hline Provider 3 & 0.000 & Ho Ditolak (sig.) \\
& & $0.000<0.05$ \\
\hline Honda Vario & 0.000 & Ho Ditolak (sig.) \\
& & $0.000<0.05$ \\
\hline Chitato & 0.000 & Ho Ditolak (sig.) \\
& & $0.000<0.05$ \\
\hline Shampo Zinc & 0.000 & Ho Ditolak (sig.) \\
& & $0.000<0.05$ \\
\hline
\end{tabular}

Sumber: Data diolah dari kuesioner dengan menggunakan SPSS version 15 for windows 


\section{Tabel 9}

\section{Pengujian secara Parsial}

\begin{tabular}{|c|c|c|c|}
\hline Studi Kasus & Variabel & Sig. & KESIMPULAN \\
\hline \multirow{4}{*}{ New Era } & Daya tarik (X1) & .156 & $.156>0.05$ (Ho tidak ditolak) \\
\hline & Kredibilitas (X2) & .003 & $.003<0.05$ (Ho ditolak) \\
\hline & Kecocokan dengan kategori produk (X3) & .003 & $.003<0.05$ (Ho ditolak) \\
\hline & Intensitas iklan (X4) & .000 & $.000<0.05$ (Ho ditolak) \\
\hline \multirow{4}{*}{ Provider 3} & Daya tarik (X1) & .010 & $.010<0.05$ (Ho ditolak) \\
\hline & Kredibilitas (X2) & .003 & $.003<0.05$ (Ho ditolak) \\
\hline & Kecocokan dengan kategori produk (X3) & .000 & $.000<0.05$ (Ho ditolak $)$ \\
\hline & Intensitas iklan (X4) & .000 & $.000<0.05$ (Ho ditolak) \\
\hline \multirow{4}{*}{ Honda Vario } & Daya tarik (X1) & .963 & $.963>0.05$ (Ho tidak ditolak) \\
\hline & Kredibilitas (X2) & .002 & $.002<0.05$ (Ho ditolak) \\
\hline & Kecocokan dengan kategori produk (X3) & .000 & $.000<0.05$ (Ho ditolak) \\
\hline & Intensitas iklan (X4) & .000 & $.000<0.05$ (Ho ditolak) \\
\hline \multirow{4}{*}{ Chitato } & Daya tarik (X1) & .801 & $.801>0.05$ (Ho tidak ditolak) \\
\hline & Kredibilitas (X2) & .000 & $.000<0.05$ (Ho ditolak) \\
\hline & Kecocokan dengan kategori produk (X3) & .000 & $.000<0.05$ (Ho ditolak) \\
\hline & Intensitas iklan (X4) & .000 & $.000<0.05$ (Ho ditolak) \\
\hline \multirow{4}{*}{ Shampo Zinc } & Daya tarik (X1) & .232 & $.232>0.05$ (Ho tidak ditolak) \\
\hline & Kredibilitas (X2) & .001 & $.001<0.05$ (Ho ditolak) \\
\hline & Kecocokan dengan kategori produk (X3) & .000 & $.000<0.05$ (Ho ditolak) \\
\hline & Intensitas iklan (X4) & .001 & $.001<0.05$ (Ho ditolak) \\
\hline
\end{tabular}

Sumber: Data diolah dari kuesioner dengan menggunakan SPSS version 15 for windows

Dari pengujian tersebut dapat dikatakan bahwa variabel X1 pada studi kasus New Era, Honda Vario, Chitato, dan Shampo Zinc tidak berpegaruh terhadap minat beli konsumen. Oleh karea itu, dapat dilihat bentuk persamaan dan nilai R square dari setiap studi kasus pada tabel berikut: 


\section{Tabel 10}

\section{Persamaan Regresi dan nilai R square}

\begin{tabular}{|c|c|c|}
\hline Studi Kasus & Persamaan & R square \\
\hline New Era & $\mathrm{Y}=2,217+0,017 \mathrm{X}_{1}+0,077 \mathrm{X}_{2}+0,150 \mathrm{X}_{3}+0,184 \mathrm{X}_{4}+\mathrm{e}$ & $45 \%$ \\
\hline Provider 3 & $\mathrm{Y}=2,982+0,030 \mathrm{X}_{1}+0,073 \mathrm{X}_{2}+0,141 \mathrm{X}_{3}+0,179 \mathrm{X}_{4}+\mathrm{e}$ & $53,7 \%$ \\
\hline Honda Vario & $\mathrm{Y}=1,976+0,000 \mathrm{X}_{1}+0,066 \mathrm{X}_{2}+0,260 \mathrm{X}_{3}+0,180 \mathrm{X}_{4}+\mathrm{e}$ & $67,9 \%$ \\
\hline Chitato & $\mathrm{Y}=1,663+0,002 \mathrm{X}_{1}+0,065 \mathrm{X}_{2}+0,239 \mathrm{X}_{3}+0,192 \mathrm{X}_{4}+\mathrm{e}$ & $73,2 \%$ \\
\hline Shampo Zinc & $\mathrm{Y}=1,108-0,012 \mathrm{X}_{1}+0,074 \mathrm{X}_{2}+0,309 \mathrm{X}_{3}+0,107 \mathrm{X}_{4}+\mathrm{e}$ & $60,1 \%$ \\
\hline
\end{tabular}

Sumber: Data diolah dari kuesioner dengan menggunakan SPSS version 15 for windows

\section{KESIMPULAN DAN SARAN}

Uji $\mathrm{F}$ menunjukkan pengaruh yang signifikan secara simultan dari seluruh variabel independen terhadap variabel dependen untuk setiap studi kasus. Selain itu, uji t menampilkan bahwa daya tarik selebriti $\left(\mathrm{X}_{1}\right)$ berpengaruh terhadap minat beli (Y) hanya pada Provider 3, sehingga dapat dikatakan bahwa daya tarik Agnes Monica tidak berpengaruh untuk sebagian besar studi kasus.

Pada studi kasus lainnya (New Era, Honda Vario, Chitato, dan Shampo Zinc), hanya 3 variabel independen lain yang berpengaruh terhadap minat beli. Oleh karena itu, dapat dikatakan bahwa kredibilitas, kecocokan dengan kategori produk, dan intensitas iklan perlu diperhatikan untuk meningkatkan minat beli konsumen.

\section{Saran}

Berdasarkan hasil kesimpulan yang ada, berikut merupakan beberapa saran yang dapat diperhatikan, yaitu:

1. Pemilihan selebriti sebagai endorser harus memperhatikan kecocokan dengan kategori dan merk produk yang diiklankan. Selebriti yang dipilih dapat dilakukan melalui pengamatan dan dilanjutkan dengan melakukan survey. Setelah itu, analisis dapat dilakukan untuk memudahkan dalam pengambilan keputusan.

2. Intensitas iklan harus ditingkatkan dengan menaikkan anggaran sehingga konsumen melihat iklan tersebut secara berulang yang kemudian diharapkan akan memunculkan minat beli. Selain itu, iklan harus ditampilkan sesuai dengan kelompok usia yang menjadi target perusahaan. 
3. Selebriti yang dipilih harus memiliki kemampuan untuk meyakinkan konsumen untuk melakukan pembelian produk.

4. Daya tarik selebriti dapat menjadi salah satu factor yang perlu diperhatikan karena konsumen secara tidak langsung melihat dari sikap, sifat, dan fisik dari selebriti.

\section{DAFTAR PUSTAKA}

Assauri, Sofjan. (2009). Manajemen Pemasaran (Edisi 1). Jakarta: Rajagrafindo Persada.

Hawkins, D.I. dan Mothersbaugh, D.L. 2010. Consumer Behavior: Building Marketing Strategy. $11^{\text {th }}$ edition. New York: McGraw-Hill.

Khatri, Puja. (2006). Celebrity Endorsement: A Strategic Promotion Perspective. Indian Media Studies Journal Vol.1 No.1.

Kotler, Philip dan Gary Armstrong. (2008). Prinsip-Prinsip Pemasaran (Jilid 2). Edisi ke-12. Penerbit: Erlangga.

Ohanian, Roobina. (1991). The Impact of Celebrity Spokesperson's Perceived Image on Consumer's Intention to Purchase. Journal of Advertising Research, 31 (1), 46-53.

Sekaran, Uma. (2003). Research Methods for Business: A Skill Building Approach (Fourth Ed.). New York: John Wiley\&Sons.

Shimp, Terrance A. (2003). Promosi dan Periklanan. Jakarta: Erlangga

Solomon, Michael R. (2002). Consumer Behavior: Buying, Having, and Being. Fifth edition. New Jersey: Prentice Hall.

www.ama.org

www.bps.ac.id

www.datastatistik-indonesia.com

www.my3q.com 